\title{
The utility of existing passerine microsatellite markers for genetic studies in endangered species: as demonstrated for a critically endangered forest bird endemic to Réunion Island, the Réunion cuckooshrike (Coracina newtoni)
}

\author{
Jordi Salmona · Deborah A. Dawson - Damien Fouillot • \\ Thomas Ghestemme $\cdot$ Christophe Thebaud . \\ Lounès Chikhi $\cdot$ Marc Salamolard
}

Received: 5 May 2010/ Accepted: 18 May 2010

(C) Springer Science+Business Media B.V. 2010

\begin{abstract}
Genetic data are increasingly recognized for their utility in conservation programs. However, many endangered species belong to families that have been understudied. Due to the urgency of their conservation status it is important to quickly identify polymorphic microsatellite loci from available resources. We show for the Réunion Cuckoo shrike Coracina newtoni, that this strategy can be very useful. Using 110 passerine microsatellite primer sets we identified eighteen polymorphic loci and tested them in 25 C. newtoni individuals. Following a Bonferroni correction one pair of loci displayed linkage disequilibrium $(P$-value $<0.0001)$.
\end{abstract}

Electronic supplementary material The online version of this article (doi:10.1007/s12686-010-9254-x) contains supplementary material, which is available to authorized users.

J. Salmona $\cdot$ D. Fouillot $\cdot$ T. Ghestemme $\cdot$ M. Salamolard Société d'Etude Ornithologique de la Réunion (SEOR), St André, Ile de La Réunion, France

J. Salmona ( $₫) \cdot$ L. Chikhi

Instituto Gulbenkian de Ciênca, Rua da Quinta Grande, no 6, 2780-156 Oeiras, Portugal

e-mail: jordi.salmona@gmail.com

D. A. Dawson

Department of Animal and Plant Sciences, University

of Sheffield, Sheffield S10 2TN, UK

C. Thebaud · L. Chikhi

Laboratoire Evolution \& Diversité Biologique, UMR 5174 CNRS-Université Paul Sabatier, 118 Route de Narbone,

Toulouse, France

M. Salamolard

Parc National de la Réunion, St Denis, Ile de La Réunion, France
Keywords Campephagidae C Coracina newtoni . Cross-species utility $\cdot$ Cuckoo shrike $\cdot$ Microsatellite . Passerine

The Réunion Cuckoo shrike, Coracina newtoni, a forest bird endemic to Réunion Island, is among the rarest and most threatened bird species in the world and was recently classified as critically endangered (IUCN 2009). The single remaining population is currently confined to a small area of $12 \mathrm{~km}^{2}$ at altitudes ranging from 1,300 to $1,800 \mathrm{~m}$ and the total population size estimate is of 70-100 individuals (SEOR 2008). The causes of such a narrow distribution range are still debated and include introduced predators (rats and cats; Thiollay \& Probst 1999; Salamolard et Ghestemme 2004; Ghestemme and Salamolard 2007).

Genetic approaches using neutral genetic markers have the potential to quickly improve our knowledge for endangered species (Allendorf and Luikart 2007) by describing diversity, inferring demographic history (e.g. Goossens et al. 2006; Johnson et al. 2009; Bourke et al. 2010). C. newtoni belongs to the Campephagidae subfamily, which contains eighty species currently listed by the IUCN, out of which 48 belong to the Coracina genus. Since no specific markers were available for Campephagidae we selected and screened a large set of microsatellite loci.

Blood sampling was conducted in the RNRE. Samples were taken from chicks just before they fledged each year between 2003 and 2009. Blood samples were kept on blotting paper and/or in a Longmire's buffer (Longmire et al. 1988). DNA was extracted by the method described by Medrano et al. (1990), and its concentration was assessed using a Nanodrop ${ }^{\mathrm{TM}}$ spectrophotometer (Thermo Fisher Scientific Inc.). 


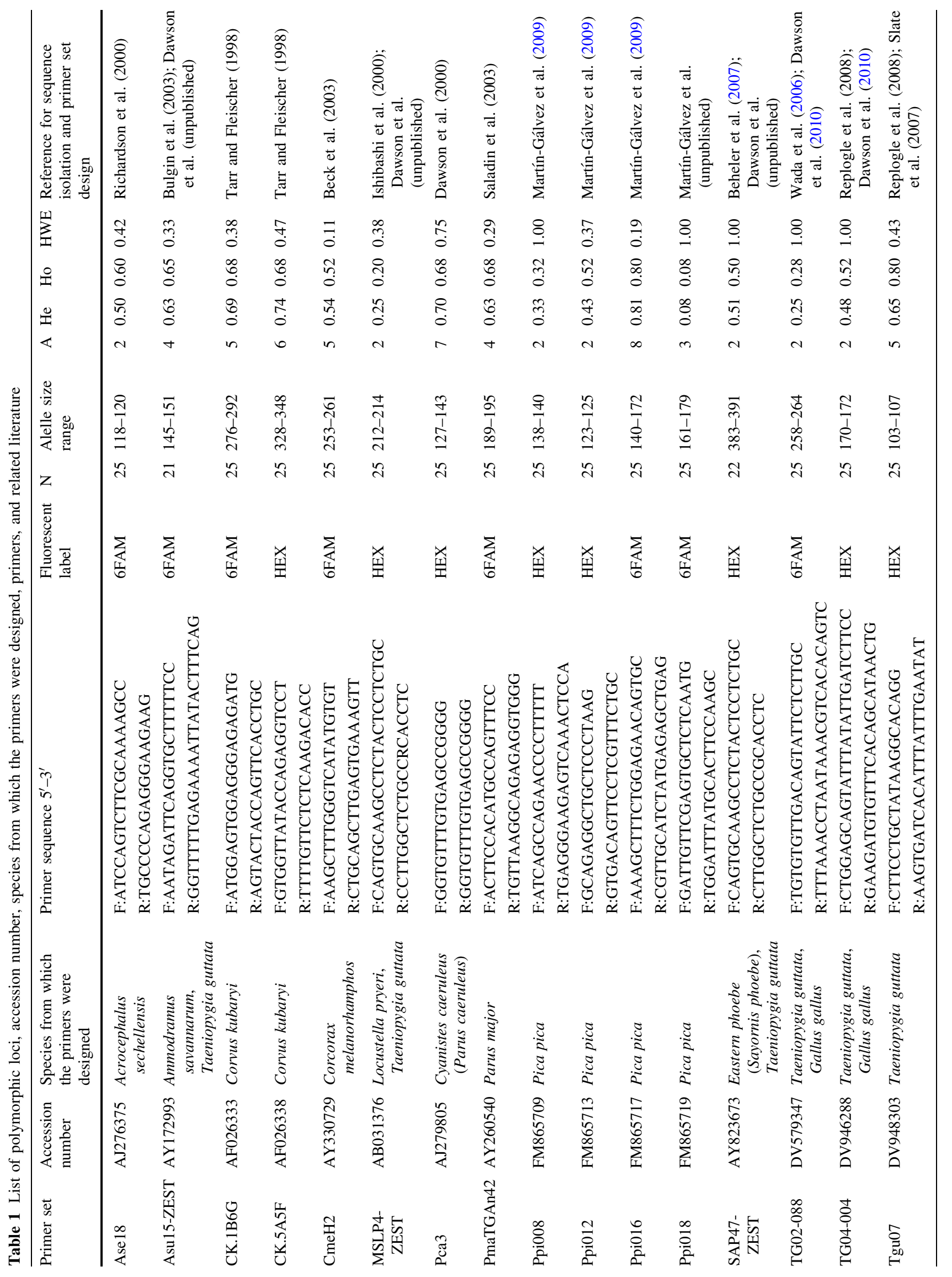


We tested a total of 110 microsatellite primer pairs (corresponding to 108 loci) for amplification (Supplementary Table 1) including 54 marker sets developed to be of high-utility in multiple species (Dawson 2007; Dawson et al. 2010; Dawson et al. unpublished data), 29 microsatellite loci developed from related corvid species (Martín-Gálvez et al. 2009) and several other loci which were known or suspected to be of high-utility based on their testing in multiple species in Galbusera et al. (2000), Lillandt et al. (2002) and from the BIRDMARKER database provided by the Molecular Ecology Laboratory of the University of Sheffield (http://www.shef.ac.uk/nbaf-s/ databases-birdmarker.html; Dawson et al. unpublished).

All 110 microsatellite primer sets were first tested on one individual for amplification using the following PCR protocol. The cycling conditions for amplification included $5 \mathrm{~min}$ at $95^{\circ} \mathrm{C}$ for polymerase activation followed by 35 cycles of $30 \mathrm{~s}$ at $94^{\circ} \mathrm{C}, 30 \mathrm{~s}$ at 50,55 or $60^{\circ} \mathrm{C}$ (i.e. three hybridization temperature were always separately tested), and $30 \mathrm{~s}$ at $72^{\circ} \mathrm{C}$ and a final elongation step consisting of $10 \mathrm{~min}$ at $72^{\circ} \mathrm{C}$. Reactions $(10 \mu \mathrm{l})$ contained Gotaq reagents (Promega) with $1.5 \mathrm{mM}$ of $\mathrm{MgCl}_{2}, 0.4$ units of Taq, $0.8 \mathrm{mM}$ of dNTPs, $0.1 \mu \mathrm{M}$ (each) of forward and reverse primers, and $10 \mathrm{ng}$ of template DNA. PCR amplification and size of the product were assessed by using $5 \%$ high resolution MetaPhor ${ }^{\circledR}$ agarose gel electrophoresis of PCR products. Both clearly and weakly amplifying products from labeled primers (all except 17, see Supplementary Table 1) were subsequently tested on ABIprism XI3130 Genotyper (Applied Biosystems). As Supplementary Table 1 indicates, 93 of the 110 primer pairs amplified, and 77 (corresponding to 75 loci) of them displayed clear amplification products close in size to that expected.

The 75 loci were tested for polymorphism using six unrelated individualsby multiplex amplifications performed using 2-6 fluoro-labeled primers pairs in a $15 \mu \mathrm{l}$ reaction using $7.5 \mu \mathrm{l} 2 \times$ Qiagen Multiplex buffer with $0.1 \mu \mathrm{M}$ (each) of forward and reverse primers, and $10 \mathrm{ng}$ of template DNA. The primers were labeled with either 6FAM or HEX (Supplementary Table 1). PCR cycling conditions for amplification included $5 \mathrm{~min}$ at $95^{\circ} \mathrm{C}$ for polymerase activation followed by of 38 cycles of $30 \mathrm{~s}$ at $94^{\circ} \mathrm{C}, 90 \mathrm{~s}$ at $58^{\circ} \mathrm{C}$ and $60 \mathrm{~s}$ at $72^{\circ} \mathrm{C}$ and a final elongation step consisting of $30 \mathrm{~min}$ at $60^{\circ} \mathrm{C}$ as recommended by the supplier. Obtained profiles were analyzed with the Peak Scanner ${ }^{\mathrm{TM}}$ Software Version 1.0 (Applied Biosystems). Based on the typing of six individuals, 43 loci were monomorphic and 10 were hard to score, the remaining 22 appeared polymorphic and were selected (Supplementary Table 1) to genotype 25 unrelated individuals.

Out of the 22 loci one appeared to be actually monomorphic (TCIIB4E), and three loci (Pdo23; Ppi011; TG01$147)$ were removed due to difficulty in peak interpretation. 
After sequential Bonferroni correction (Rice 1989), linkage disequilibrium was detected using GENETIX 4.05.2 (Belkhir et al. 2004) between one pair of loci (SAP47 and $\mathrm{CmeH} 2, P$-value $<0.0001)$. None of the eighteen polymorphic scorable loci (Table 1) departed from HardyWeinberg equilibrium using a Markov-chain method implemented in GENEPOP v.4.0 (Rousset 2008). No null alleles or other amplification errors were detected using MICRO-CHECKER (van Oosterhout et al. 2004), in any of the 18 loci (Table 1). One locus (TGZ-037), known to be sex-Z linked in various passerine species (Dawson 2007; Dawson et al. unpublished data) was also found to be Z-linked in C. newtoni.

Our study indicates that from starting with 108 microsatellite loci we were able to identify 18 polymorphic loci in a highly endangered bird with a very low population size. This proportion (ca. 17\%) suggests that even if it is necessary to test many microsatellite loci to identify polymorphic ones, there is currently a large enough database to identify a reasonably large set of usable microsatellites for many endangered passerine species. We believe that the microsatellite markers we have successfully identified will be crucial to study genetic diversity in the numerous endangered Campephagidae species of the Indian Ocean and elsewhere.

Acknowledgments We would like to acknowledge Jean Francois Centon and Jery Larose, for identifying the nests, Magalie Thierry, Hélène Delatte, Anthony Bouetard and Thierry Joët for their help and advices during the lab work, and the Centre International de Recherche Agronomique pour le Développement (CIRAD) of St Pierre de La Réunion for allowing our work in their laboratory. This work is part of the C. newtoni's conservation and research program managed by the "Société d'Etude Orhnithologique de la Réunion" (SEOR) which was founded by the French "Ministère de l'Ecologie et du Developpement Durable" and European Fund for Regional Development (FEDER). The SEOR's work in the "Réserve Naturelle de la Roche Ecrite" is also supported the "Département Réunion".

\section{References}

Allendorf FW, Luikart G (2007) Conservation and the genetics of populations. Wiley-Blackwell, Oxford

Beheler AS, Fike JA, Rhodes OE (2007) Eight new polymorphic microsatellite loci from the eastern phoebe (Sayornis phoebe). Conserv Genet 8:1259-1261

Belkhir K, Borsa P, Chikhi L, Raufaste N, Catch F (2004) GENETIX 4. 0. 5. 2., Software under Windows ${ }^{\mathrm{TM}}$ for the genetics of the populations. Laboratory Genome, Populations, Interactions, CNRS UMR

Bourke BP, Frantz AC, Lavers CP, Davison A, Dawson DA, Burke TA (2010) Genetic signatures of population change in the British golden eagle (Aquila chrysaetos). Conserv Genet. doi 10.1007/ s10592-010-0076-x

Dawson DA (2007) Genomic analysis of passerine birds using conserved microsatellite loci. PhD Thesis, University of Sheffield, UK

Dawson DA, Horsburgh GJ, Küpper C, Stewart IRK, Ball AD, Durrant KL, Hansson B, Bacon I, Bird S, Klein Á, Lee J-W, Martín-Gálvez D, Simeoni M, Smith G, Spurgin LG, Burke T (2010) New methods to identify conserved microsatellite loci and develop primer sets of high utility - as demonstrated for birds. Mol Ecol Resour 10:475-494

Galbusera P, van Dongen S, Matthysen E (2000) Cross-species amplification of microsatellite primers in passerine birds. Conserv Genet 1:163-168

Ghestemme T, Salamolard M (2007) Réunion Cuckooshrike, Coracina newtoni, endemic species in danger. Ostrich 78:255-258

Goossens B, Chikhi L, Ancrenaz M, Lackman-Ancrenaz I, Andau P, Bruford MW (2006) Genetic signature of anthropogenic population collapse in orang-utans. PLoS Biol 4:285

IUCN, International Union for Conservation of Nature (2009) Endangered species Red List: http://www.iucnredlist.org/apps/ redlist/search

Johnson JA, Tingay RE, Culver M, Hailer F, Clarke ML, Mindell DP (2009) Long-term survival despite low genetic diversity in the critically endangered Madagascar fish-eagle. Mol Ecol 18:54-63

Lillandt BG, Bensch S, Hansson B, Wennerberg L, Von Schantz T (2002) Brief report Isolation and cross-species amplification of microsatellite loci in the Siberian jay (Perisoreus infaustus). Hereditas 137:157-160

Longmire JL, Lewis AK, Brown NC, Buckingham JM, Clark LM, Jones MD, Meincke LJ, Meyne J, Ratliff RL, Ray FA et al (1988) Isolation and molecular characterization of a highly polymorphic centromeric tandem repeat in the family falconidae. 1. Genomics 2:14-24

Martín-Gálvez D, Dawson DA, Horsburgh GJ, Burke T (2009) Isolation, characterization and chromosome locations of polymorphic black-billed magpie Pica pica (Corvidae, AVES) microsatellite loci. Mol Ecol Resour 9:1506-1512

Medrano JF, Aasen E, Sharrow L (1990) DNA extraction from nucleated red blood cells. Biotechniques 8

Rice WR (1989) Analyzing tables of statistical tests. Evolution 43:223-225

Rousset FC (2008) Genepop'007: a complete re-implementation of the genepop software for Windows and Linux. Mol Ecol Resour 8:103-106

Salamolard M, Ghestemme T (2004) Plan de conservation de l'Echenilleur de la Réunion, Coracina newtoni. Unpublished Report SEOR/DIREN/FEDER/Département de la Réunion, p 34

SEOR (2008) Co-gestion de la Réserve de la Roche Ecrite, Bilan des activités 2008. Unpublished Report, 31pp

Thiollay JM, Probst JM (1999) Ecology and conservation of a small insular bird population, the Réunion cuckoo-shrike Coracina newtoni. Biol Conserv 87:191-200

van Oosterhout C, Hutchinson WF, Wills DP, Shipley P (2004) MICRO-CHECKER: software for identifying and correcting genotyping errors in microsatellite data. Mol Ecol Notes 4:535538

Wada K, Howard JT, McConnell P et al (2006) A molecular neuroethological approach for identifying and characterizing a cascade of behaviorally regulated genes. Proc Natl Acad Sci USA 103:15212-15217 